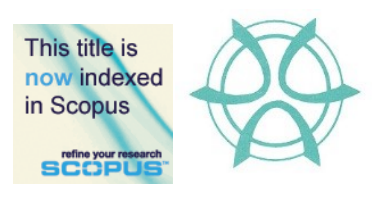

PLANNING MALAYSIA:

Journal of the Malaysian Institute of Planners

VOLUME 19 ISSUE 4 (2021), Page $304-315$

\title{
PERSPECTIVES ON MALAYSIA'S LACK OF IMPLEMENTATION OF GREEN BACK LANES
}

\author{
Lukman Hakim bin Mahamod ${ }^{1}$, Syakir Amir Bin Ab. Rahman², Aaliyah Bajrai \\ binti Ahmad $^{3}$ \\ ${ }^{1,2,3}$ Urban and Regional Planning, \\ Kulliyyah Architecture and Environment Design \\ INTERNATIONAL ISLAMIC UNIVERSITY MALAYSIA
}

\begin{abstract}
Malaysia has been utilising green back lanes since the ' 90 s. In spite of the several benefits of these lanes, such as the formation of active spaces, decrease in runoff water, and visitor attractions, green back lanes are yet to be deployed in the residential regions of Malaysia, prompting the question as to why these lanes have not yet been installed extensively. The objectives of this research work were: to determine what experts opined regarding the installation of green back lanes in the country, study the scenarios which caused the absence of implementation, produce a report showing the outcomes and analysis, and offer suggestions. The researcher deployed the interview strategy for ascertaining the views and standpoints of architects, town planners, maintenance staffs, project managers, and marketers on the dearth of green back lane installation. The research emphasises on the aspects of cost, maintenance, and safety.
\end{abstract}

Keywords: back lane, green back lane, green alleys

\footnotetext{
${ }^{1}$ Assistant Professor at International Islamic University Malaysia. Email: lukmanh@iium.edu.my
} 
PLANNING MALAYSIA

Journal of the Malaysia Institute of Planners (2021)

\section{INTRODUCTION}

This study presents a critical perspective on the inadequate deployment of green back lanes in Malaysia and identities three crucial concerns. The first concern is that the green back lanes are exclusively installed in high-cost accommodations and affluent strata housing in Malaysia. Therefore, there is a bit of a misunderstanding among the communities that green back lanes are extremely imprecise spaces. The next concern is that several back lanes in residential areas have been unsafe for the inhabitants. The residents believe that lanes which are accompanied with gentle landscapes and lights are much safer. The green back lanes make the inhabitants feel insecure as someone can pass by from the backside of their homes. The third concern is that the presence of a green back lane makes it tough for public utility suppliers to gain access to the property for building, repairing, and up keeping utility lines. Hence, infrastructure and upkeep could be the aspect driving the dearth of implementation of such lanes in the country. follows:

Thus, to accomplish the primary objective, two goals are formulated as

i) To ascertain the opinion of professionals on installation of green back lanes in Malaysia.

ii) To study the aspects of safety, maintenance, and cost in the installation of green back lanes in Malaysia.

\section{BACK LANES: AN OVERVIEW}

A back lane is a thin road located between rows of constructions, utilised as a general public track (Tawil, Lias, Usman, Yusoff, Che Ani \& Kosman, 2013). It is also called as alley. It is an unfavourable street which is typically been ignored by the residents. This statement is supported by Li (2014), Ford (2001), and Aniza, Nurhayati, Mohamad, Rosniza and Aliyah (2016).

Table 1: Back lanes as unutilised spaces

\begin{tabular}{ll}
\hline \multicolumn{1}{c}{ Author (Year) } & \multicolumn{1}{c}{ Statement } \\
\hline Li (2014) & $\begin{array}{l}\text { Alleys or back lanes used to be places that were easy } \\
\text { to be forgotten in such discourse }\end{array}$ \\
\hline Ford (2001) & $\begin{array}{l}\text { Alleys became displeasure because they were } \\
\text { threatening, risky, and unsound places }\end{array}$ \\
\hline $\begin{array}{l}\text { Aniza, Nurhayati, Mohamad, } \\
\text { Rosniza and Aliyah (2016) }\end{array}$ & $\begin{array}{l}\text { The back lane area of the house is not a potential } \\
\text { quality space for daily activity and be neglected as } \\
\text { positive spaces }\end{array}$ \\
\hline
\end{tabular}

These statements indicate that before today, a majority of individuals paid little attention to the back lane on the limited area, which is typical for a residential terrace region 
Lukman Hakim bin Mahamod, Syakir Amir Bin Ab. Rahman, Aaliyah Bajrai binti Ahmad

Perspectives On Malaysia's Lack of Implementation of Green Back Lanes

The Planning Standard and Guidelines offered by PLANMalaysia (JPBD) describe the back lane as the separation between the rows where houses are constructed. Malaysian laws address the back lane: Street, Drainage and Building Act 1974 (Act 133). Subsection 69 (1), Street, Drainage and Building Act 1974 [Act 133] specifies a back lane as a built or planned accessible area (or its parts), including entry points and estate specified for present or future use as an alley, including multiple alleys, drainage system, and other aspects linking a back lane. Act 133, Section 68 specifies local regulations where a back alley is declared open for public use. Typically, when a rear hallway is provided to the authorities, it is designated a public area regardless of its form. Jabatan Kerja Raya (JKR) specifies that a back lane (including those behind buildings) is open for use by public transport based on specific rules.

\section{FACTORS THAT CONTRIBUTE TO THE LACK OF GREEN BACK LANE IMPLEMENTATION IN MALAYSIA Maintenance of Green Back Lanes}

As the green back lanes are implemented under strata landed titles, they need to conform to specific acts like the Housing Developers (Control and Licensing) Act 1966, Strata Titles Act 1985, National Land Code Act 1965, Building and Common Property (Maintenance and Management) Act 2007, and the newest Strata Management Act 2013. Strata landed titles are regulated under Strata Management Act 2013 (SMA) and the Strata Titles Act 1985, which also safeguard and control land parcels having strata titles. These guidelines manage the division of constructions into plots and strata title lands, along with their management and maintenance. Payment of sinking fund and maintenance fee, for instance, is required under SMA 2013. Every parcel holder is exclusively accountable for the maintenance and overhaul of his/her parcel along with any accessory plots. The upkeep of the collective plot is a joint obligation of all parcel holders. Thus, a medium is necessary to aid the Management Corporation's or developer's appropriate regulation and upkeep of the common possessions.

A back lane should help avert the proliferation of fire and aid fire operations. It should also function as an escape path as well as a space to navigate in times of emergencies. The Fire and Rescue Department has mandated a minimum stipulation of 3,048 meters (10 feet) as victim rescue access and for dousing fires from the backside of the structure. Therefore, the written permission, called planning permission, of the Local Planning Authority is required by the implementers. Planning permission is required following attainment of land conversion agreement if the building proposals are to move forward. The question is: how will maintenance be carried out in the green back lanes, will it be costlier, and will people be ready to help in the upkeep of the green back lanes and shell out the maintenance fees? 
PLANNING MALAYSIA

Journal of the Malaysia Institute of Planners (2021)

\begin{abstract}
Safety
Experts have expressed contrasting opinions regarding safety of residents' safety when back lanes are provided. The favourable view certainly comes from government organisations like PLANMalaysia, which greatly recommend installation of back lanes as a place to warrant owners' privacy between the rows of residential properties and as a location for calm illumination and ventilation among buildings so as to create a favourable and wholesome environment. Conversely, as per Kuo, Bacaicoa and Sullivan (1998), people felt most apprehensive in heavily covered landscape regions and relaxed in open and wellpreserved areas. The safety factors pertain to not just physical but also nonphysical aspects like culture and religion. The influence of non-physical aspects in the dearth of installation of green back lanes is because of the country's culture and people's reluctance to acclimatise. As noted by Bavani (2020), the inhabitants at Taman Bukit Indah complained that back lanes are not safe and might cause health issues.
\end{abstract}

\title{
High Cost
}

The socioeconomic standing of a residential zone too has an influence on the pricing. Nevertheless, new information has been uncovered, considering the resilient green cover protecting the neighbouring areas. Hardie and Nickerson (2004) asserted that construction cost involving tree protection could be up to $5.5 \%$; however, builders could offset their investment by demanding additional maintenance charges and command a better market price. Cromption (2001) indicated that residential properties with better natural aspects, including proximity to open areas and parks, are about $8 \%$ to $20 \%$ more valuable than similar properties. The price premium starts declining as the distance from such expanses approaches a half-mile.

\section{METHODOLOGY}

Considering the Movement Control Order (MCO), semi-structured interviews were conducted through a Web-based platform. Maximum Variation Sampling was utilised for choosing samples from every unit of study. This method is based on purposeful filtering instead of random selection. It encompasses choosing a small number of samples with an assortment of attributes for attaining a varied outcome. Consequently, the quality of the outcomes assumes priority over the number of respondents. An individual with the knowledge of administering a project or installing green back lanes was selected as the sample. The researcher will obtain a variety of standpoints on the lack of installation of green back lanes in Malaysia, given the assortment of sample attributes.

As the participants responded in Bahasa Melayu, the transcription procedure was quite challenging. After all transcripts are collected, the researcher will carry out a thematic analysis. This is a technique of methodically defining 
Lukman Hakim bin Mahamod, Syakir Amir Bin Ab. Rahman, Aaliyah Bajrai binti Ahmad

Perspectives On Malaysia's Lack of Implementation of Green Back Lanes

all the key ideas which surface from the interviews and then classifying and cultivating them into generic themes. Partially-structured interviews require even more time than the structured ones because of the need to develop coding frames and perform content assessment on a huge number of interviews. The questioner will either write the replies or record them on a tape. Hence, in this research, the data processing is performed manually instead of using a computer. It means that all the data acquired from the interviews has been converted into English, and the key highlights from all the interviews of the samples have been assembled into one topic.

Each participant was allotted a code. For instance, 'GTP' represents participant number 1 who belongs to the category of government sector town planner.

Table 2: Code references based on the respondents' backgrounds

\begin{tabular}{lll}
\hline Code & Respondent's Background & Number \\
\hline $\boldsymbol{G T P}$ & Government town planner & 3 \\
\hline $\boldsymbol{P T P}$ & Private town planner & 1 \\
\hline $\boldsymbol{P} \boldsymbol{A R}$ & Private architect & 3 \\
\hline $\boldsymbol{P P M}$ & Private project manager & 1 \\
\hline $\boldsymbol{P M} \boldsymbol{N}$ & Private maintenance worker & 1 \\
\hline $\boldsymbol{P M} \boldsymbol{T}$ & Private marketer & 1 \\
\hline $\boldsymbol{T o t a l}$ & & 10 \\
\hline
\end{tabular}

\section{DATA ANALYSIS AND RESULT}

The outcomes attained from the assessment of the responses of the participants have resulted into two primary themes, which are landscape back lane and active back lane. The following table shows the themes derived from the responses of the participants.

Table 3: Respondents' responses on the definition of 'green back lane'

\begin{tabular}{ll}
\hline & $\mathbf{\%}$ \\
\hline Active Back Lane & \\
\hline Back lane as exercise spaces & 80 \\
\hline Back lane as tourism attractions & 60 \\
\hline Back lane as business site & 20 \\
\hline Landscape Back Lane & 20 \\
\hline Back lane fill with soft scape & \\
\hline
\end{tabular}

Three parameters that have caused the lack of Green Back Lane's implementation in Malaysia have been examined to attain the objectives. First one is the maintenance. The second one is considerations for safety. Finally, the third 
PLANNING MALAYSIA

Journal of the Malaysia Institute of Planners (2021)

parameter is the cost. The following table shows the themes and subthemes derived according to the responses of the participants.

Table 4. Respondents' responses on causes lack implementation of the green back lane in Malaysia

\begin{tabular}{ll}
\hline & $\%$ \\
\hline Maintenance & \\
\hline Involvement of management body & 100 \\
\hline Complicated approval building process & 80 \\
\hline Demanding maintenance & 30 \\
\hline Safety & 100 \\
\hline Physical Safety & 80 \\
\hline Visual Privacy & 70 \\
\hline Emotional Safety & 100 \\
\hline Maintenance fees & 100 \\
\hline Aesthetic fees & \\
\hline
\end{tabular}

The assessment of the outcomes leads to the answer for the study of the 3 objectives. The study also demonstrated that cost, safety, and maintenance all proved to be the factors leading to the lack of the implementation of the green back lane in Malaysia. All the participants had different viewpoints. For the maintenance parameter, $100 \%$ were in agreement regarding the complexity of the green back lane process. Also, $100 \%$ of the participants agreed that the lack of green back lanes implementation in Malaysia is because of management involvement, $80 \%$ of them agreed that the building approval procedure is tedious, and $30 \%$ of them agreed that the green back lanes need a great deal of maintenance. In case of safety factor, the absence of green back lanes implementation in Malaysia can be attributed to the fact that $100 \%$ of the participants agreed on physical safety, $80 \%$ of them agreed on the visual privacy, while $70 \%$ of them agreed on the emotional safety. Also, $100 \%$ of the participants agreed that cost was a factor in the lack of green back lane implementation in Malaysia.

\section{DISCUSSION OF FINDINGS}

\section{Advantages of Provision Green back Lane}

Most of the respondents considered green back lanes to be an active area. As per $8 / 10$ respondents, a green back lane can be defined as a back lane with active spaces. Even if 2/10 respondents would agree with this, they also added that the greenery maintained in the back lane would welcome others to come and participate in various activities. 
Lukman Hakim bin Mahamod, Syakir Amir Bin Ab. Rahman, Aaliyah Bajrai binti Ahmad

Perspectives On Malaysia's Lack of Implementation of Green Back Lanes

As mentioned by PAR1, a green back lane can be regarded as a fun and lively back lane, which invites people to do plenty of activities in the parks. Also, an active green back lane is good for community centres, offering numerous benefits to the community overall, and even for senior citizens. This also created a spot for people to do various things in the green back lane. For instance, during COVID-19 pandemic, people were restricted from going out in public, which also resulted in various health issues and socioeconomic issues like higher divorce rate as well as mental health drowning. With green back lanes, senior citizens were able to take a daily stroll in proximity to their home in order to maintain their fitness. Using the green back lane also helped Alzheimer's patients.

As per GTP2, green back lanes allowed people to take a break from negative social environment. People who were trapped at their homes during Movement Control Order (MCO) tended to get more stress. In such a situation, green back lanes helped facilitate social interactions as people could take a walk or chat with the neighbour near their house area. As per PPM1, green spaces were used as active places since individuals who are used to visiting parks and open spaces frequent were three times more likely to attain prescribed levels of physical activity versus non-users. For exercise, people tended to prefer nearby parks and open areas that were more appealing and open.

Since concrete and asphalt materials are lesser in green back lanes, this allowed growing certain plants and vegetables, performing mural painting, and also setting a few chairs and picnic tables in the area for activities. As per PTP4, the project also offered 'a beautiful walkable, public area to attract more crowd towards local businesses. For example, mural paintings displayed in the back lane at Bandar Maharani in Muar, Johor, gave a more positive, clean and bright environment to the community. With this example, green back lane will also attract a greater number of tourists, which would eventually boost local business economy, as well as simultaneously accomplish the city's goal to get revitalised.

\section{Lack of Green Back Lane Implementation in Malaysia}

As per the study, two interrelated phenomena that could have resulted in the above-mentioned issue were: 1) planning and maintenance; 2) religion and culture. However, the major contribution was from planning and maintenance.

With regards to planning and maintenance, extended approval procedure is regarded to be a key factor. For instance, the concept of green back lanes was used for strata landed houses instead of non-strata landed houses, and the building approval process involved all of the town planners. As per GTP1, GTP2, GTP2, and PTP1, implementing green back lanes required involvement of various management bodies and included a complex approval process, which was in line with the statement of Marzukhi et al. As per (2020), getting approval for the landscape with regards to the back lane plan was regarded to be a challenging stage in the Malaysian planning process. A certain gap is required amongst the 
PLANNING MALAYSIA

Journal of the Malaysia Institute of Planners (2021)

rows of the buildings in order to prevent fires from spreading and making the task easier for firefighters, in case a fire breaks out. During emergencies, it also acted as an escape route without congestion. Not just that, the back lane is also regarded as a path forward for utilities and infrastructure. Thus, implementers need to keep space for a green back lane in order to offer alternate routes during an emergency or to be used as alternative utility route. The main cause of delays in refurbishing such projects is the complicated approval system for getting authorisation from the local government. A delay would add up to the project's anticipated cost. This may explain the reason why even though the adoption of green back lanes in Malaysia goes back to the 1990s, not much significant residential development has happened in terms of utilising them. As per GTP2, greater efforts are needed in the submission process. This includes various components, such as construction plan approval, submission of development permission application, infrastructure plan approval, and other procedures mandatory for the verification of the building's Principal Submitting Plan (PSP) complying to all government rules and regulations. This is because of the developers' need to persuade the departments of alternative emergency and utility route, including technical drawings and designs and, and also convince them on how maintenance would be established.

Another factor associated with the first phenomena would be the cost of maintenance. Also, these maintenance costs can change at any moment. The primary responsibility pertaining to $\mathrm{MC}$ includes maintenance and administration of the common land, and also any property that has been entrusted towards it, in a proper and serviceable condition. The Commissioner of Building (COB), Managing Agent, the Joint Management Body, and the Management Corporation are all partners associated with the strata property management, along with areas of building repair, office administration management, inventory management, coordination and processing of operation and maintenance costs. Table 3 shows the maintenance activities that have been highlighted by a respondent (PMN1). Due to this, the residents refrain from paying higher greater maintenance costs, which is the main reason for the poor adoption pertaining to green back lanes in Malaysia. This finding was backed by Hardie and Nickerson (2004), which stressed upon the statement that even though construction costs for lots with trees conserved could reach up to $5.5 \%$, developers could earn back their money by increasing the costs of maintenance and thus also get higher market rates.

Cost factor associated with high maintenance can be attributed towards the lack of effectively implementing green back lane in Malaysia. Maintenance fees have been seen to impact the buyers' perceptions towards the house, because of the associated exclusivity and expensiveness. This list was provided to PMN1 in order to get information regarding Malaysia's green back lane maintenance activities as well as frequency. The table below presents the list and answers: 
Lukman Hakim bin Mahamod, Syakir Amir Bin Ab. Rahman, Aaliyah Bajrai binti Ahmad

Perspectives On Malaysia's Lack of Implementation of Green Back Lanes

Table 5. List of maintenance frequency and activities according to PMN1

\begin{tabular}{|c|c|c|}
\hline & Maintenance Activities & Frequency \\
\hline \multirow[t]{3}{*}{$\begin{array}{l}\text { Native } \\
\text { Landscaping }\end{array}$} & $\begin{array}{l}\text { Check for and rid unnecessary vegetation, } \\
\text { such as weeds }\end{array}$ & $\begin{array}{l}\text { Every } 3 \text { months or as } \\
\text { needed during } \\
\text { growing season }\end{array}$ \\
\hline & $\begin{array}{l}\text { Remove and replace any dead and diseased } \\
\text { plants }\end{array}$ & $\begin{array}{l}\text { Every } 3 \text { months or as } \\
\text { needed }\end{array}$ \\
\hline & Thin crowded vegetation & Every 3 to 4 months \\
\hline \multirow[t]{4}{*}{$\begin{array}{l}\text { Permeable } \\
\text { Pavements }\end{array}$} & $\begin{array}{l}\text { Leaves, lawn clippings, mulch, sediment, } \\
\text { and litter can all be checked. }\end{array}$ & Every 2 to 3 months \\
\hline & $\begin{array}{l}\text { To better avoid clogging and ensure water } \\
\text { flows across the pavement, sweep it } \\
\text { (consult product recommendations) }\end{array}$ & $\begin{array}{l}\text { After heavy rain or } \\
\text { once a year }\end{array}$ \\
\hline & $\begin{array}{l}\text { To prevent unwanted plants in street } \\
\text { spacing, maintain any adjacent planting } \\
\text { areas. }\end{array}$ & Every day \\
\hline & $\begin{array}{l}\text { Inspect the pavement for sunken, broken, } \\
\text { or incomplete units/sections and repair or } \\
\text { substitute the aggregate between the } \\
\text { pavers as required. }\end{array}$ & Once a year \\
\hline Greenways & $\begin{array}{l}\text { Check to see if the water is drained } \\
\text { correctly and not ponding. }\end{array}$ & $\begin{array}{l}\text { Often (once a } \\
\text { month) or as needed } \\
\text { after rain }\end{array}$ \\
\hline
\end{tabular}

The phenomenon pertaining to religion and culture has a role to play towards ineffective implementation of green back lane. This finding was in line with the earlier study carried out by Bavani (2020). As per most of the respondents, which included consultant and local authority, the provision of green back lane also needs to consider other people's backgrounds, such as status, religion as well as cultural beliefs. In Malaysia, the kitchen is normally built near a back lane where, with regards to green back lane housing, people may actively walk passing through the kitchen. In such case, Muslim women stated their concern of feeling uncomfortable when people walking by would see them cooking in the kitchen. They were worried if the maintenance workers or neighbours would see their aurat when they are cooking at the kitchen. This is because they believe that Muslim women need to protect their aurat from the sight of non-mahrams. With regards to peoples' belief pertaining to Feng Shui views, the kitchen is regarded as a sign of prosperity, and thus any concerns that could hinder the peace need to be dealt with caution.

Concerning the mentioned observations, respondents GTP2 and GTP3 indicated the challenges about creating green back-lanes for residential areas where building age exceeds ten years. Citizens know the benefits of creating green back-lanes and the health aspects of green lane environments; however, there is a resistance against such implementations. Moreover, in contrast with 
PLANNING MALAYSIA

Journal of the Malaysia Institute of Planners (2021)

planned residential regions, it is challenging to renew back lanes after obtaining approval for older residential regions.

\section{Strategies to Encourage Green Back Lane Implementation in Malaysia}

This research identified two emphasis areas that should be employed to motivate people to create green back-lanes: 1) Indulging residents and creating a system using the bottom-up scheme; 2) Creating a green back-lane knowledge base.

Involving the locals comprises the bottom-up technique where the objective is to reduce maintenance expenditure. The GTP1 indicates that the green back-lane concept was initiated by Jawatankuasa Kemajuan dan Keselamatan Kampung (JKKK) (also called Resident Association) to create a green aspect about the back lanes. In Indonesia, the Depok City is an appropriate example of residents' cooperation to create a green back-lane. Residents collaborate to create such lanes, negating the need to involve many administrative units, simplifying the system and reducing costs. Moreover, it is feasible to reduce maintenance costs too. Social aspects like the religious and local way of life can be smoothened because neighbourhood agreement is critical.

In the handbook context, the administration should hand over the reckoner for references concerning builders and develops to motivate sustainable architecture and landscaping methods to help reduce floods, create a maintenance system, cost plan, and implement Crime Prevention Through Environmental Design. The Chicago Department of Transportation (CDOT) launched the Green Alley Handbook to motivate the adoption of best management processes (BMP) for Chicago and neighbouring areas' alleys. The department also wanted to address infrastructure issues caused by higher temperatures and precipitation.

\section{CONCLUSION}

It is observed that green back-lanes provide several environmental, systematic, and social advantages; however, there is a lack of widespread adoption because of several reasons. Cautionary processes and appropriate action have been established for administrative focus to facilitate the implementation of this social benefit. These actions are expected to increase green adoption, which is critical for the present environment. People have powerful ideas and know the benefits and consequences; however, several aspects hinder the implementation of such ideas.

\section{ACKNOWLEDGEMENTS}

We would like to express our thanks to everyone who has contributed directly and indirectly towards the preparation of this paper.

\section{REFERENCES}


Lukman Hakim bin Mahamod, Syakir Amir Bin Ab. Rahman, Aaliyah Bajrai binti Ahmad

Perspectives On Malaysia's Lack of Implementation of Green Back Lanes

Abd Wahab, S. R. H., Che-Ani, A. I., Omar, H., Ibrahim, M., \& Mamat, M. (2017). The management fund classification to determine reliable maintenance fees of highrise residential in Malaysia. International Journal of Supply Chain Management, 6(1), 220-225.

Alhojailan, M. I. (2012). Thematic analysis: A critical review of its process and evaluation. West East Journal of Social Sciences, 1(1), 39-47.

Aniza, A. B, Nurhayati A.M, Mohamad, A.M, Rosniza. O., \& Aliyah, N.Z.S. (2016). Housing space quality towards quality of life: A case study of double storey terrace houses. In MATEC Web of Conferences (Vol. 66, p. 00083). EDP Sciences.

Bavani M. (2020). When added security makes it unsafe. https:/www.thestar.com.my/metro/metro-news/2020/10/27/when-addedsecurity-makes-it-unsafe [Accessed 14 March 2021].

Cassidy, A., Newell, J., \& Wolch, J. (2008). Transforming alleys into green infrastructure for Los Angeles. USC Center for Sustainable Cities.

Crompton, J.L. 2001. Parks and Economic Development. PAS Report No. 502. American Planning Association, Chicago, Illinois.

Engström, G., \& Gren, A. (2017). Capturing the value of green space in urban parks in a sustainable urban planning and design context: pros and cons of hedonic pricing. Ecology and Society, 22(2).

Hardie, I., and Nickerson C. 2004. The Effect of a Forest Conservation Regulation on the Value of Subdivisions in Maryland. WP 03-01 (Revised). Department of Agricultural and Resource Economics, University of Maryland, College Park, 35 $\mathrm{pp}$

Kuo, F. E., Bacaicoa, M., \& Sullivan, W. C. (1998). Transforming inner-city landscapes: Trees, sense of safety, and preference. Environment and behavior, 30(1), 28-59.

Kristiyantoro, B., \& Simarmata, H. A. (2019, November). Self-governing "Green Alley" implementation as the Solution to address environmental challenge of public housing in Depok City. In IOP Conference Series: Earth and Environmental Science (Vol. 338, No. 1, p. 012004). IOP Publishing.

Li, S. (2014). Green infrastructure planning in an urban context:" green plans" in four Winnipeg inner-city neighbourhoods.

Malaysia, \& International Law Book Services, L. R. B. (2006). Street, Drainage and Building Act, 1974 (Act 133): (as at 20th February 2006). Selangor: International Law Book Services.

Marzukhi, M. A., Leh, O. L. H., Khalid, N. S., \& Jaafar, A. (2020). The Building Plan Approval Process for Residential Development in One Stop Centre. Case Study: Subang Jaya Municipal Council, Selangor. Journal of Surveying, Construction and Property, 11(2), 40-49.

Montpetit, N., \& Octeau, S. (2020, June 4). Green Alleys of Montreal. WWF.CA. https://wwf.ca/biopolis-projects/green-alleys-of-montreal/.

PLANMalaysia (JPBD), Planning Standard and Guidelines of Back Lane 2014.

Seymour, M., Wolch, J., Reynolds, K. D., \& Bradbury, H. (2010). Resident perceptions of urban alleys and alley greening. Applied Geography, 30(3), 380-393.

Siti L. F., Tawil, N. M., USMAN, I. M., \& Mutalib, A. A. (2016). Socio-Spatial Integration of Landscape Back Lane of Housing At Bandar Baru Nilai: Privacy 
PLANNING MALAYSIA

Journal of the Malaysia Institute of Planners (2021)

And Community. Journal of Engineering Science and Technology, 11(5), 673683.

Shuhana, S. B., \& Natasha, H. A. (2013). Safe city concept and crime prevention through environmental design (CPTED) for urban sustainability in Malaysian cities. American Transactions on Engineering \& Applied Sciences, 2(3), 223-245.

Tawil, N. M., Lias, S. M., Usman, I. M. S., Yusoff, N. I. M., Ani, A. C., \& Kosman, K. A. (2013). Evolution of back lane design: A view of terrace housing in Malaysia. Asian Social Science, 9(15), 277.

United States Bureau of Diplomatic Security (2020). Annual Crime and Safety Report 2020. Retrieved 15 April 2021, from https://www.osac.gov/Content/Report/148f55ab-9111-47ef-99e4-1811a5d28a20. Issued by Overseas Security Advisory Council (OSAC)

Via Capitale (2021). The benefits of green alleys: Why reclaim these city spaces? Retrieved $15 \quad$ February 2021, from https://www.viacapitalevendu.com/blogue/newsroom/the-benefits-of-greenalleys-why-reclaim-these-city-spaces/

Wolter, S. K. (1999). Feng shui: Chinese principles of interior arranging (Doctoral dissertation).

Received: $25^{\text {th }}$ August 2021. Accepted: $13^{\text {th }}$ October 2021 